\title{
BEST-SELLER E GAMES: A INICIAÇÃO DO JOVEM NO UNIVERSO LITERÁRIO
}

\author{
Jéssica Kurak Ponciano* \\ Arilda Ines Miranda Ribeiro **
}

\begin{abstract}
RESUMO: É facilmente constatável a falta de interesse pela literatura esboçada pelos jovens do Ensino Médio. Também são constantes as queixas dos professores com relação ao gosto cultural dos alunos, bem como seu afastamento do universo literário. Ao contrário dessa realidade, o interesse dos adolescentes pelo universo virtual dos games cresce consideravelmente, bem como os produtos que se originam de suas famosas franquias, como os Best-sellers. O artigo a seguir tem como objetivo refletir sobre a aplicabilidade dos games e dos Best-Sellers como ferramenta de inserção do jovem na literatura. Será abordada brevemente a conceituação e história do surgimento da Literatura de Massa, bem como as diferenças entre a literatura pertencente ao cânone e o Best-Seller. Trataremos das questões de formação de leitores por meio da narratividade dos Jogos Digitais. Em seguida será proposta uma reflexão sobre a aplicabilidade das leituras de massa e dos jogos digitais nas salas de aula, visando aumentar a adesão dos jovens à leitura.
\end{abstract}

PALAVRAS-CHAVE: Best-seller. Game. Leitura. Jovem Leitor.

\section{Introdução}

Observa-se, em várias esferas do ensino público e privado, especialmente no ensino médio, uma baixíssima adesão dos jovens ao universo da literatura. Fato facilmente verificável nos discursos dos professores ao afirmarem que os alunos não lêem nem mesmo os livros cujas indicações são requisitos para avaliações; e dos estudantes quando esboçam sua desaprovação com relação aos livros que Ihes são solicitados para leitura. Em consonância com o obstáculo anterior, podese notar ainda o uso constante e único da literatura clássica no processo de ensino e aprendizagem de literatura. Sobre esse fator Tavela (2010) explica:

A escola assumiu para si a decisão a respeito da adequação de textos e a legitimação de determinadas práticas de leitura, na tentativa de defender e

\footnotetext{
* Universidade Estadual Paulista "Júlio de Mesquita Filho", Presidente Prudente, Brasil. Imeio: jessica.kpp22@gmail.com

Universidade Estadual Paulista "Júlio de Mesquita Filho", Presidente Prudente, Brasil. Imeio: arilda@fct.unesp.br
} 
valorizar o que selecionou ser importante para formar leitores. Assim, a escolha dos textos que serão "trabalhados" é feita de maneira arbitrária, o que quase sempre provoca no jovem uma certa aversão pelos livros. (TAVELA, 2010, p. 2)

O ensino de literatura dá-se de modo diacrônico e sincrônico, por isso é necessária a teorização das obras clássicas, bem como sua contextualização no momento histórico em que ela se encontra inserida.

Um dos maiores desafios da Educação na contemporaneidade é a produção de estratégias que contribuam no processo formativo de jovens e adultos que apreciem a leitura e vejam nela um universo rico e criativo. A educação para a literatura deve ser pautada na ampliação dos horizontes do leitor, apresentando a literatura como uma rica fonte de busca e construção de diferentes modos de compreensão do mundo. Para fundamentar a complexidade e o desafio na produção de crianças e jovens apreciadores do universo literário recorre-se à terceira edição da pesquisa "Retratos da leitura no Brasil", realizada pelo Instituto Pró-Livro. Nessa pesquisa enfatizamos o seguinte dado: o número de Nãoleitores ${ }^{1}$ aumentou 5\% do ano de 2007 para o ano de 2011, e a pesquisa foi realizada com um total de 173 milhões de pessoas no ano de 2007, contra 178 milhões de entrevistados no ano de 2011.

Os dados acima descritos podem ser relacionados também à existência de um grande contingente de professores frustrados por acreditarem que não obtiveram sucesso no propósito de despertar o gosto dos adolescentes pela literatura. Muitos estudantes são apáticos à fruição literária, crendo que todos e quaisquer livros são maçantes, afastando-se cada vez mais do universo literário. Apesar dos tétricos resultados apontados pela pesquisa "Retratos da leitura no Brasil", existe um contingente enorme de obras literárias que fazem sucesso, principalmente entre o público jovem.

\footnotetext{
${ }^{1}$ Definição de Leitor e Não-leitor apresentada pela pesquisa Retratos da leitura no Brasil. Leitor: é aquele que leu, inteiro ou em partes, pelo menos um livro nos últimos três meses. Não-leitor é aquele que não leu nenhum livro nos últimos três meses, mesmo que tenha lido nos últimos doze.
}

Texto Digital, Florianópolis, v. 10, n. 1, p. 102-115, jan./jul. 2014. ISSNe: 1807-9288 
Muitas delas são oriundas de famosos games, outras tantas são adaptadas ao cinema, lotando bilheterias do mundo todo, conquistando uma legião de fãs e despertando o interesse de milhares de pessoas, mais especificamente do público que se encontra em idade escolar.

Esses textos que possuem um grande impacto mercadológico dentro da cultura de massa são muitas vezes execrados e abolidos das salas de aulas pelos professores mais conservadores que acreditam que a academia deve primar exclusivamente por aquilo que é efetivamente artístico e cientifico, ignorando as expressões culturais e artísticas da contemporaneidade.

Um mercado notadamente ascendente é o mercado da literatura de massa oriundo da releitura de narrativas digitais extraídas de famosas franquias de games. Como exemplo pode-se mencionar a prestigiada franquia de jogos intitulada Diablo, criada pela empresa de softwares Blizzard, que, após o grande sucesso de vendagem dos jogos, transformou parte do seu enredo em romance.

Diante disso muitas perguntas surgem: de onde surgiram o conceito e a diferenciação entre a alta literatura e o Best-Seller? Por que os Best-Sellers e Games atraem tanto a atenção dos jovens em idade escolar? Como utilizar os Best-Sellers e os Games a serviço da inserção do jovem no universo literário? O artigo tenciona responder a algumas dessas inquietações e propõe uma reflexão a respeito das principais questões que envolvem a polêmica dos Best-Sellers e dos Games, principalmente no âmbito educacional.

\section{Os Games: relações com a formação do jovem leitor}

É de amplo conhecimento o modo como o universo dos Games ganha cada vez mais espaço no cotidiano dos jovens em idade escolar. De acordo com Alves (2008), em meados da década de oitenta, iniciam-se as investigações sobre a relação dos jogos eletrônicos com os processos de aprendizagem; e um dos pioneiros nessa linha foi o teórico Greenfield (1988) com o estudo do 
desenvolvimento do raciocínio na era da eletrônica, enfatizando a televisão, os computadores e os videogames (ALVES, 2008, p. 3).

Com esse fenômeno, torna-se necessária a reflexão sobre a forma como esse fato influencia na formação intelectual e cultural dos adolescentes. Os adultos, e mais especificamente os professores, podem utilizar esse fator de modo estratégico, elaborando técnicas de trabalho a fim de utilizar essas mídias a seu favor e não tê-las como inimigas, perpetuando o preconceito popular de que elas são prejudiciais no processo de construção do conhecimento discente. Segundo Amaral e Paula 2007:

\begin{abstract}
Os jogos eletrônicos compõe um fenômeno tecnocultural recente. Em meados da década de 1970, começaram a ser vendidos aos milhões, tornando-se objetos de entretenimento e lazer em várias regiões do globo, desde o mundo capitalista ocidental até boa parte dos países asiáticos.

Se inicialmente poucos eram adeptos dessa prática, o mesmo não e pode dizer nos dias de hoje, em que o mercado de jogos já supera em faturamento a indústria do cinema e possui previsão de um crescimento contínuo nos próximos anos. (AMARAL; PAULA, 2007, p. 364)
\end{abstract}

Nota-se então que as questões que tangem a formação cultural contemporânea são pautadas nas novas tecnologias, e, por isso, faz-se necessário aprender a conviver com elas ao invés de negá-las.

Graças ao grande contingente de jovens que aderem a esse novo estilo de entretenimento, surgem com eles uma vasta parcela de leitores, que, ávidos pelas "narrativas" contidas em seus jogos prediletos, consomem uma significativa quantidade de materiais relacionados a determinadas franquias de jogos digitais.

A título de exemplo podemos mencionar a famosa série de jogos denominada "Assassin's Creed", que, além de obter grande sucesso na vendagem do software, criou também uma série de romances baseada no jogo. A série produzida pelo autor Oliver Bowden é uma das maiores campeãs de venda entre o público jovem, caracterizando-se, portanto, como um Best-seller. Porém, como assegura Alves (2008):

Texto Digital, Florianópolis, v. 10, n. 1, p. 102-115, jan./jul. 2014. ISSNe: 1807-9288 
Penso que uma trilha ainda a ser seguida passa pela formação dos nossos docentes. Como crianças e adolescentes, os professores precisam imergir nos âmbitos semióticos que entrelaçam a presença das tecnologias na sociedade contemporânea. Levar os jogos digitais para a escola por que seduzem os nossos alunos, sem uma interação prévia, sem a construção de sentidos, buscando enquadrar esse ou aquele jogo no conteúdo escolar a ser trabalhado, resultará em um grande fracasso e frustração por parte dos docentes e dos discentes. (ALVES, 2008, p. 3)

\section{Surgimento e conceituação do Best-Seller}

Com as mudanças ocorridas no mundo ocidental após fenômeno da Revolução Industrial, nota-se um crescente aumento no número de pessoas alfabetizadas. Esse crescimento iminente de pessoas letradas faz com que o mercado capitalista comece a voltar suas atenções para um novo tipo de mercado: o mercado livreiro e/ou literário. A partir daí descobre-se que a literatura, não mais como imaginavam os formalistas e os críticos literários, possui, além da função crítica e artística, a função comercial e de entretenimento.

Com a democratização do Ensino, os livros que até então circulavam apenas entre uma pequena parcela da população, que desfrutava de bens de consumo e de uma educação formal privilegiada, passam a fazer parte também do cotidiano de um público que, apesar de não possuir educação acadêmica tão singularizada, era alfabetizado. Dessa forma, o livro aos poucos tornou-se um bem acessível a todos, ou seja, um produto para o consumo das massas. Cabe lembrar também que, segundo Leontiev (1978), as desigualdades existentes entre as camadas são produtos de desigualdades econômicas, de classes e também das consecutivas desigualdades de relações com as aquisições que encarnam as aptidões e faculdades da natureza (LEONTIEV, 1978, p. 267).

Como ponto de partida para uma nova concepção literária, como foi dito acima, excedia as dimensões críticas e reflexivas, inicia-se um processo de simplificação formal e produção de obras com linguagem acessível às massas. A qualidade das obras e produções literárias e culturais passa por um processo de revalorização 
no mercado consumidor e também para a parcela da população que compunha o senso comum.

Se antes eram os aspectos artísticos e formais que davam qualidade às produções literárias, agora elas passam a ter seus valores atribuídos a partir da quantificação das vendas, ou seja, pelo seu sucesso ou fracasso com o público consumidor. A escala de valorização de uma determinada obra passa a ser diretamente redirecionada pelo mercado, inicia-se a disputa constante pelo espaço relativo aos padrões vigentes até então, sendo que esses padrões primavam única e exclusivamente pela quantidade de vendagens em detrimento da qualidade do produto literário.

A respeito disso, acrescenta-se, segundo Leontiev (1978), a acentuada ausência de condições de acesso à arte e aos bens culturais pelas classes desfavorecidas que se dá justamente pela concentração material de bens das classes dominantes (LEONTIEV, 1978, p. 255). Essas classes economicamente desafortunadas por muito tempo foram submetidas a um precário desenvolvimento cultural e um débil sistema de acesso à educação formal e acadêmica. Em consequência desses fatores as classes dominantes utilizaram-se dos bens materiais e culturais ao seu bel prazer, estratificando-os.

Diversos fatores, como o aumento do desenvolvimento e disseminação dos artefatos tecnológicos, trouxeram consigo várias mudanças no cotidiano do trabalhador braçal no período pós-Revolução Industrial. Começava-se a pensar em seleção de mão de obra qualificada e na parcela de trabalhadores que até então permaneciam analfabetos, bem como naqueles que começavam a fazer parte do mundo da produção escrita e literária e passam a ver nos livros, de modo geral, um símbolo de erudição e objeto de formação do conhecimento. Quando o livro passa a ser ressignificado pela massa trabalhadora e pela burguesia, estes também passam a consumi-lo com muita assiduidade. 
Paralelo ao acesso dos livros pelas camadas sociais economicamente desfavorecidas e com precária inserção no sistema educacional, os avanços tecnológicos e as ambições capitalistas enxergam nesse mercado um crescente índice de sucesso, instigando cada vez mais o consumo dos livros e os produzindo em maiores escalas; buscando também uma redução de seus preços. Redução de valores e alto número de tiragens que só foram possíveis com a difusão e a criação tecnológica de máquinas de impressão.

\section{Alta literatura versus Best-Seller, como separar?}

A noção de Best-Seller ocorreu em meados do século XIX, na França, com o surgimento da literatura de folhetim. Essa configuração de produção textual era publicada em uma seção do jornal, como um rodapé. Inicialmente publicavam-se trechos adaptados de romances que já haviam sido lançados em forma de livros. Essas publicações possuíam uma ligação entre si, sendo uma sequencial à outra.

Essa estratégia de publicação foi bastante aceita pelo público, aumentando consideravelmente os índices de vendagem dos jornais; sendo, portanto, mais comercializado, carecendo assim de um número maior de tiragens. $A$ consequência direta desse evento foi a queda do valor dos jornais, tornando-os mais acessíveis a todos, inclusive àqueles que não pertenciam às camadas sociais mais abastadas. Tempos depois, essas histórias publicadas nos jornais são copiladas e transformam-se em romances que serão considerados os campeões de venda. Eliana Paz (2004) afirma que nas listas dos livros mais vendidos da contemporaneidade circulam, em sua grande maioria, quase que de forma unânime, as obras literárias voltadas para o entretenimento, sendo muito raro de ser encontrada uma obra literária clássica (PAZ, 2004, p. 5).

A escrita e a seleção dos conteúdos dos folhetins eram feitas a partir da análise do gosto e da capacidade de abstração do operariado e da burguesia. Desse modo, as produções começaram a buscar a utilização da linguagem cotidiana, a busca de arranjos gramaticais simples, contendo períodos curtos e fabricando 
enredos que se assemelhassem com a vida cotidiana daqueles que a consumissem. Segundo Aranha e Batista (2009):

O folhetim, antecessor do best-seller, instaurou um modelo de narrativa fracionado, constituindo-se em uma corrente cujos elos eram acrescentados a cada volume do jornal em que eram publicados, edificando-se lentamente perante o leitor. (ARANHA; BATISTA, 2009, p. 126)

Os personagens passam a ser planos e rasos, não há grandes conflitos, bem como grandes ideias que necessitem de um prévio apreço pela arte para serem compreendidas.

Há também o modo negativo de tratamento e recepção da literatura de massa pela crítica literária. Considerada uma leitura de cunho "inferior", destinada apenas à fruição, o Best-Seller foi por muito tempo visto apenas por esse meandro. Porém, sabiamente Umberto Eco (2000) diferencia o conceito de baixa literatura e literatura de massa do conceito de literatura de entretenimento (ECO, 2000 , p. 37). Tomamos como exemplo uma das obras de maior sucesso da atualidade: As Crônicas do Gelo e do Fogo, de autoria do romancista e roteirista norte-americano George R. R. Martin, sendo muito bem recebida pela crítica em geral e vendendo aproximadamente quinze milhões de exemplares mundialmente. Essa saga (composta até agora por cinco livros já publicados) vem sendo indicada a vários prêmios de fantasia e ficção científica (ARAÚJO, 2011).

Essa produção trata de um período de guerra civil entre diferentes famílias, todas elas buscam conquistar o trono de ferro. A guerra é ambientada em um universo fantástico. Na busca sobre informações oficiais sobre o escritor, verifica-se o trabalho intelectual de Martin ao debruçar-se arduamente sobre conflitos e guerras históricas para, assim, obter verossimilhança em sua produção. Desse modo depreende-se que, durante a escrita de seus romances, George Martin elabora um caro trabalho de produção e escrita, visando elaborar artisticamente seus escritos. 
É justamente o trabalho de valorização estética dada à obra pelo autor que vai ou não the conferir um status de alta literatura ou apenas de literatura de mercado. Nas Crônicas do Gelo e do Fogo nota-se claramente a presença de vários elementos que compõe também as obras clássicas como: linguagem rebuscada, personagens complexos e esféricos, descrições longas e detalhadas, entre outras; e, ao lado delas, observamos também características de romances de folhetim como: catarse, tensão e clímax.

Buscar exemplos de literatura de massa e baixa literatura não é custoso quando a contemporaneidade é analisada enquanto período de produção literária. Dentre os livros que circulam como os mais vendidos nas famosas revistas em circulação do país, pode-se elencar a saga Crepúsculo. A trilogia produzida pela escritora Stephenie Meyer atingiu grande sucesso de bilheterias em suas adaptações cinematográficas, que geraram lucros milionários. Porém, a obra em si foi alvo de severas críticas. Razão pela qual essa obra é intitulada baixa literatura pela crítica literária.

As personagens da saga Crepúsculo são rasas, os conflitos são aparentes, há, ao longo do romance, algumas falhas na verossimilhança; a obra toda foi escrita e pautada no gosto popular de adolescentes, preferencialmente do sexo feminino. Consideram-se também as questões formais e de acessibilidade da língua presentes na saga Crepúsculo. A obra é composta de vocabulário simples, que pouco exige conhecimento vocabular do público consumidor, isso se dá de modo intencional por parte da autora; não sendo, portanto, um desleixo em relação aos seus leitores, mas sim um meio de tornar sua obra facilmente compreensível ao público que a mesma pretende atingir.

Após definir e exemplificar as conceituações de alta literatura e Best-Seller, podese inferir que uma determinada obra, ainda que não seja considerada clássica pelo cânone literário, pode, ao mesmo tempo, ser qualificada como Best-Seller e possuir características semelhantes àquelas encontradas em produções literárias tidas como clássicas. A Alta literatura pertence a um núcleo de produção que 
contempla aspectos estéticos de produção literária, enquanto os Best-Sellers representam a baixa literatura, ou sub-literatura, valendo-se de uma investigação apurada sobre os gostos culturais vigentes, umas vez que quanto mais uma obra atenda aos anseios populares, maior será seu índice de vendagem e mais êxito ela apresentará diante do mercado livreiro.

\title{
Aplicabilidade do Best-Seller como ferramenta de inserção do adolescente no universo da alta literatura
}

$\mathrm{Na}$ tentativa de romper com o preconceito existente contra os Best-Sellers e utilizá-los na constituição e inserção dos adolescentes no universo literário por meio da fruição, e considerando sempre a evolução do jovem que tomará contato com essa literatura, pode-se recorrer à interessante reflexão de José Paulo Paes, defensor da "Teoria do Degrau", que aborda a questão da literatura de entretenimento e da ficção científica despido de relativismos:

\begin{abstract}
Talvez cause estranheza ter-se falado até agora só de um nível popular e de um nível médio na literatura de entretenimento, deixando de fora um eventual nível superior. Este já seria o da literatura erudita ou de proposta, onde há de igual modo um propósito de entretenimento, embora de natureza mais sutil e menos "fisiológica", se assim se pode dizer que nos dois outros níveis. $\mathrm{E}$ em relação a esse nível superior aliás que uma literatura média de entretenimento, estimuladora do gosto e do hábito da leitura, adquire o sentido de degrau de acesso a um patamar mais alto onde o entretenimento não se esgota em si, mas traz consigo um alargamento da percepção e um aprofundamento da compreensão das coisas do mundo. (PAES, 1990, p. 28)
\end{abstract}

Os meios educacionais tendem a acompanhar as evoluções sociais, históricas e sociais; razão pela qual os métodos pedagógicos necessitam se adaptar a essas novas realidades postas. Sendo assim é seguro que os métodos educativos devam buscar pontos comuns entre as vivências da juventude no mundo atual, e a literatura de fruição pode, com sucesso, subsidiar tal relação.

Trabalhar, incentivar, bem como discutir a função social da literatura na sala de aula é papel do professor, porém despertar o real gosto pela leitura se torna uma tarefa árdua quando esse trabalho se utiliza apenas de obras eruditas e consagradas pelo cânone literário. Muitos estudantes não se identificam com 
obras clássicas, julgando-as maçantes e obsoletas, pois esses livros não apresentam uma conexão direta com as vivências do público que se pretende atingir. Dessa forma, nota-se a importância da iniciação do aluno no universo literário primeiramente através de leituras de fruição.

Outro aspecto que possibilitará as discussões em sala de aula é a problematização das formas de opressão que afastam a cultura erudita das camadas populares, levando aos estudantes a ideia de alienação cultural e econômica, trabalhada por Leontiev (1978) ao afirmar que a alienação econômica, fruto da divisão social do trabalho, acarreta não só o afastamento da cultura intelectual das massas, resultando também uma formação de cultura declinante produzida para atingir e ser consumida por essa mesma massa (LEONTIEV, 1978, p. 239). A produção da qual trata o autor pode ser associada à baixa literatura.

Ao longo do processo de ensino, é esperada a evolução do conhecimento acadêmico do alunado, e, nessa etapa, torna-se fundamental a associação dentre a literatura de fruição e as obras literárias eruditas. Nesse quesito Vygotsky afirma que:

[...] as formas mais desenvolvidas da arte são a chave das formas atrasadas, como a anatomia do homem o é em relação à dos macacos e não ao contrário. [...] Análise da reação estética indica que a finalidade da investigação não consiste na exposição sistemática da doutrina psicológica da arte em todo seu volume e amplitude (todas as variedades da arte, todos os problemas, etc) nem sequer a investigação indutiva de uma série determinada de fatos, mas sim justamente a análise dos processos em sua essência. (VYGOTSKY, 1991, p. 374-375)

Na citação acima Vygotsky enfatiza a importância da realização de um trabalho centrado nas obras clássicas, umas vez que elas são a gênese da apropriação e da essência das formas mais atrasadas de arte.

Tendo como base as reflexões anteriores, pode-se afiançar que o docente deve explorar a possibilidade de trabalho com obras que não são clássicas, cuidando sempre da intencionalidade educacional que cada obra literária terá junto ao 
processo de ensino e aprendizagem de seus discentes. Se por um lado é necessário despertar nos jovens em idade escolar o interesse pela leitura, é também conveniente que esse indivíduo, após a aquisição do hábito de leitura, se torne crítico com relação àquilo que será selecionado futuramente por ele enquanto leitor.

\section{Conclusão}

Após as conceituações e reflexões realizadas, nota-se que o trabalho com a instrumentalização da literatura de massa e a utilização de jogos digitais com a finalidade de formação de leitores jovens apresenta-se como potente ferramenta. A complexidade desse trabalho é óbvia, porém necessária, exigindo primeiramente uma ruptura com os preconceitos atribuídos aos Best-Sellers e aos Games e um conhecimento sistematizado deles para que sua leitura não se decline apenas no quesito do entretenimento e do relativismo.

É preciso pautar o trabalho com a leitura em aspectos de construção de consciência humana e política. Trazer um Best-Seller para a sala de aula significa abordar com os discentes todos os seus aspectos positivos, bem como estabelecer críticas em relação ao seu modo de produção e a sua função ideológica e mercadológica. O professor deve primar pelo aluno crítico e reflexivo e não apenas voltar sua atenção à leitura única e exclusivamente alienante e consumidora.

Muitos docentes caem nessa armadilha também com as obras clássicas; pois, a partir do momento que não possuem o domínio do conteúdo das mesmas, passam-nas aos alunos, que muitas vezes não compreendem sua finalidade e não avançam no processo de construção do conhecimento e no acesso aos bens culturais. Afinal o papel da escola é o de promoção da emancipação e reflexão e não apenas reprodutor de conteúdos prontos. 


\title{
BEST-SELLER E GAMES: INITIATION OF THE YOUNG IN LITERARY UNIVERSE
}

\begin{abstract}
It is easily verifiable lack of interest in literature sketched by young high school students. Are also constant complaints from teachers in relation to the cultural liking of the students as well as their distance from the literary universe. Contrary to this fact, teenage interest in the virtual world of games grows considerably, as well as products that originate from their famous franchises such as best-sellers. The following article aims to reflect on the applicability of the games and Best-Sellers as the young insertion tool in the literature. Will be briefly discussed the concept and history of the emergence of Literature Mass, as well as differences between literature belonging to the canon and the best-seller. We'll tackle the issues of educating readers by means of the narrative of Digital Games. And then will be proposed reflection on the applicability of the readings and mass of digital games in the classroom, to increase the adhesion of young people to read.
\end{abstract}

KEYWORDS: Bestseller. Game. Reading. Young Reader.

\section{REFERÊNCIAS}

ALVES, Lynn. Relações entre os jogos digitais e aprendizagem: delineando percurso. Educação, Formação \& Tecnologias; v.1, n. 2, p. 3-10, nov. 2008. Disponível em: <http://eft.educom.pt>. Acesso em: 18 jul. 2014.

AMARAL, S. C. F.; PAULA, G. N. A nova forma de pensar o jogo, seus valores e suas possibilidades. Pensar a Prática, Goiânia, v.10, n. 2, 2007.

ARANHA, Gláucio; BATISTA, Fernanda. Literatura de massa e mercado. Contracampo, Niterói, v. 20, n. 1, p.121-131, ago. 2009. [Semestral]

ARAÚJJO, Mayara de. O inverno está chegando. Diário do Nordeste - Caderno n. 3 3, 2011. Disponível $<$ http://diariodonordeste.globo.com/materia.asp?codigo=1047294>. Acesso em: 25 fev. 2013.

ECO, Umberto. Apocalípticos e integrados. Série Debates 19. São Paulo: Perspectiva, 2000.

LEONTIEV, Alexis. O homem e a cultura. In: 0 desenvolvimento do psiquismo. Lisboa: Horizonte Universitário, 1978.

PAES, José Paulo. Por uma literatura brasileira de entretenimento (ou: o mordomo não é o único culpado). São Paulo: Companhia das Letras, 1990.

PAZ, Eliane H. Massa de Qualidade. In: I Seminário Brasileiro sobre o Livro e História Editorial, 2004, Casa de Rui Barbosa, Rio de Janeiro. Disponível em: <www.livroehistoriaeditorial.pro.br/pdf/elianehpaz.pdf>. Acesso em: 25 fev. 2013. 
TAVELA, Maria Cristina Weitzel. Literatura de massa na formação do leitor literário. Darandina Revisteletrônica, Juiz de Fora, v. 3, n. 1, p. 1-10, nov. 2010.

Texto recebido em: 05/06/2014.

Texto aceito em: 14/07/2014. 